\title{
Rationale Management Approach in Stress Management: An Information Perception
}

\author{
${ }^{1}$ Vijaya Kumar, V.T.R., ${ }^{2}$ R. Dhaneesh and ${ }^{3}$ R.V. Siva Balan \\ ${ }^{1}$ Department of Business Administration, St. Xavier's Catholic College of Engineering, Nagercoil, India \\ ${ }^{2}$ Department of Business Administration, Narayanaguru College of Engineering, India \\ ${ }^{3}$ Department of Computer Applications, Noorul Islam University, Thuckalay, India
}

Received 2012-11-19, Revised 2012-12-20; Accepted 2013-03-12

\begin{abstract}
Occupational stress has both positive and negative impact. By tweaking stress causing factors, the positive and negative impact of occupational stress can be proscribed. By default, stressors have a degree of proportion pertaining to the type of organization. Manipulation of the existing proportion results in consideration of tradeoff among stressors. Control on job is considered as a factor of providing job satisfaction. An optimal way of affording task related information can be the availability of tools to access and assess decision information. Providing access to the precise rationale at similar instances may help the employee to get better solution, thus job satisfaction. Information by means of information systems'can be considered as primary level intervention to avoid certain role stressors.
\end{abstract}

Keywords: Occupational Stress, Role Stressors, Moderators, Satisfaction

\section{INTRODUCTION}

Occupational stress has steadily more turn out to be a hassle for many organizations. Stress felt by employees may source cataclysm in the progress of ongoing project context or it may cause as catalyst for a successful mission. IT organizations are more vulnerable for the impact of stress. Stress generally crop up from inconsistent precedence and conflicting priorities. Managing the deficiency in the career forecasting and mitigating pressure activities can tackle the inherent stress causes.

It is stretch all through the IT business beside the point of hierarchical level in management systems. The study related stress should be certainty dealt by every employee individually or as a group, at all level of job hierarchy. Necessity of current situation in managerial practice is the amendment of stressors to get the outcome in a positive manner. The role of the stress and its causes can be used for high productive environment, by exploring the positive aspect of its strategy management. This can be evidenced from the book of Seyle (1956). A physician explains the general-adaptation-syndrome concept and advocates on the subject of the stress as: "stress is not necessarily something bad it all depends on how you take it. The stress of exhilarating, creative, successful work is beneficial while that of failure, humiliation or infection is detrimental" (Seyle 1973). There are several professionals who enhance the quality of their work and comprehend the job satisfaction (Parker and Decotiis, 1983) by utilizing and witnessing the pressures of heavy workloads and deadlines as positive challenges. The stress model and practices followed by any organization should consider strategies for the positive impacts as well as negative impacts of the stressors.

Here, we illustrate the stress model (Fig. 1) for negative consequences from the Stephen Robbin's "Organizational Behaviour" (Robbins and Judge, 2007). Dr. Robbin's research has covered the stressors on its negative impression to provide positive managerial outcome. His research has focused on conflict, power and politics in organizations, behavioral decision making and the development of effective interpersonal skills.

Corresponding Author: Vijaya Kumar, V.T.R., Department of Business Administration, St. Xavier`s Catholic College of Engineering, Nagercoil, India 


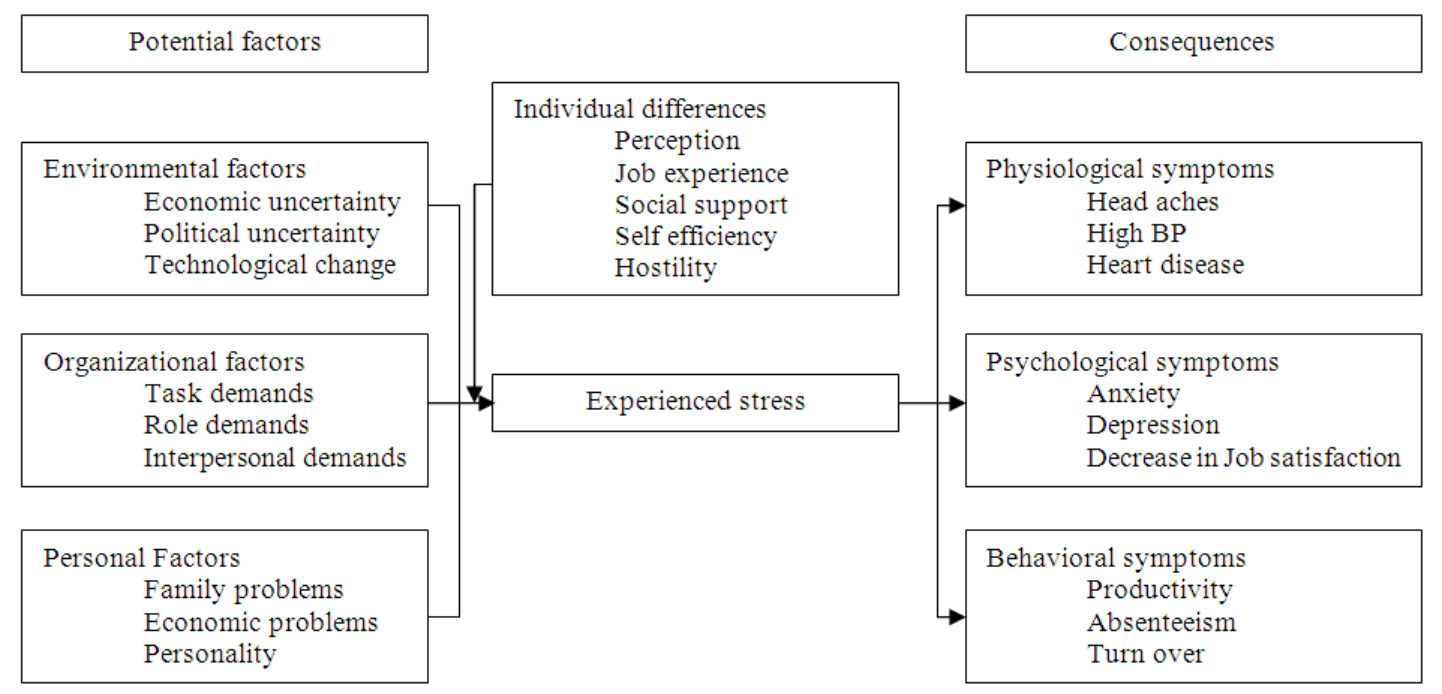

Fig. 1. The stress model-negative consequences

Stress is sign of pressure from the study environment, subsequently converted into strain within a person. If the sign of pressure are not handled properly, it challenges the realization of individual goals, thus indirectly influence the overall organizational goals. Whilst accessible resources are inadequate on the way to deal with the demands and pressures of the circumstances; first, it affects the individuals 'psychologically and then haunts the physical state that results in poor performance, which could be properly managed to get positive outcome. In the direction of acquiring positive outcomes as of a stress circumstances, individuals, call for to regulate their emotions and directly deal with their thinking and behaviors their work stress by practice (Schaufeli and Bakker, 2004; Singh, 2000). All through the exertion process of self-regulation depletion (Muraven and Baumeister, 2000; Vohs and Faber, 2007; Wan and Agrawal, 2011), the attempt drawn in for coping with stress guzzle a fractional puddle resources used for self-regulation practices. A lot in indication of work stress be capable of timely persuade the employees to seek homeostasis (Singh, 2000) by inducing self-regulatory mechanisms that use up self-regulation resources.

\subsection{Literature Review}

Impact of workplace stress (Blaug et al., 2007) affects the problem solving capabilities and subsequent job satisfaction (Elfering et al., 2005; Jonge et al., 2001). Stress problems at work place can be elaborated by the application role theory, thus the contribution of pressures to the occupational stress can be comprehensively revealed. Although the dynamics of role stress and its internal components regarding other professions in other background are reasonably acknowledged (Rutter et al., 2002; Narayanan et al., 1999), understanding the causes of role stress among IT professionals is of paramount importance for their well-being and formulation of stress management programs. Organizational Role Stress (ORS) scale developed by Pareek (2002) has been represented as allusion for advancement of research tools for such programs. Indeed, Pestonjee (1999) observed that ORS is one of the best tools available for gauging the role stress. Srivastav (2009) ratified the significance of previous research on ORS. The theoretical significance of the findings of previous studies is noteworthy as they had tried to explore the antecedents of organizational role stress applicable for IT domains. 'Role Indistinctness' Role Excess Role Invasiveness 'Role Divergence, Role Augmentation, Self-Diminution Role Fortification' and 'Resource Shortage' are the classifications found as antecedents of the role stress.

Marmot (2005), projects the stress at the positions of lower status employees, associating the stress with lack of control. Lack of control is result of the situation in which the employee is left without providing the information to take appropriate decision on a task which he is undergoing. Studies reveal that the occupational stress has the potential to "cost organizations millions of dollars each year through lost productivity, absenteeism, accident and insurance payouts" (Sutherland et al., 1995). Frequently, literatures on occupational stress, projects the theories of "role" and "person-environment fit". 
Drawing from an information processing perspective, researchers were examining how the Information Technology (IT) has been a catalyst in the form of organization structure (Dibrell and Miller, 2002) evolution. For the most part, causes of work stress concern are about the system of work design (Fig. 2) and the means by which organization are managed. Organizational stress can be noted as an emotional, cognitive, behavioral (Gendolla, 2000) and physiological response to the aggressive and harmful aspects of work, work environment and organizational climate. It is a condition characterized by feelings of helplessness in solving tasks. The employees need to be competitive in order to sustain their reputation of the job. Once they should contribute new products, else, on other hand work smarter to maintain low cost with good service. The adverse effects of stress result in impediment to job performance and to change the undertaken process. The effects may be seen in poor job performance, high levels of absenteeism, discontent among the workforce, high turnover of labor with the loss of "good" employees and a large increase in recruitment and re-training costs (McHugh and Brennan, 1992).

Interpersonal consequences of stress induce a compromise in the training and development initiatives. The intellectual and emotional consequences are directly proportional to the effect of compromise induced by stress. Training, Re-engineering, Collaborative team works are impacted by the individuals affected by stress. Rather than coherent theories, the social environment work model is based on underlying conceptual categories which are interrelated. The categories identified with in this model are objective environment and subjective environment. Objective environment rely on the organizational characteristics such as size, hierarchy and job description. Whereas subjective environment is a part of employees 'perception (psychological environment) as reviewed by Lewin (1951). The psychological environment is built by the phenomena of role conflict, role ambiguity and role overload.

The six work roles, regardless of individuals 'vocational choices are elaborated and empirically studied by Osipow (1998). Those are the roles utilized in the revised version of Occupational Stress Inventory (OSI). They include role ambiguity, role insufficiency, role overload, role boundary, responsibility and physical environment. Responsibility with availed physical environment are the essentials for a new inhabitant for that role, during his initial time of commitment with necessary information (Al-Zhrani, 2010) and suitable access tools will be helpful in undertaking the responsibility for the authorized task activities. In the realized theory (French et al., 1982), it has been proved that if there are no accurate fit between the employee and his environment, there strain is palpable.

\subsection{Conceptualization}

The frameworks for development/maintenance of information systems involve various phases, activities and task sets. Each and individual task set may be executed on some decision. Eventually, the product of such activities may be related to the reasoning documents, to sustain the decision information. On other hand, if an intellectual employee, considered as significant part in constructing a information system exits the organization, there come a vacuum of reasoning for the decisions (during the development of such information system). In certain scenario, the usage of tools provide information to the fresher reduce the chances of victimizing to stress.

Preserving the specifications of decisions (Balan and Punithavalli, 2011) and all their inter dependencies with knowledge rules will support the evolution and maintenance of information systems developed in IT Organizations. By preserving the previous decisions, the precise successful decisions can be re-used in future. Because, decision authority and learning opportunities had specific and independent impact on subjective health, psychological functioning, coping style and organizational outcome variables. Opportunities to learn the necessary information to decide on the undergoing task can reduce the stress to give satisfaction for employee. Interaction affects between demands, learning opportunities and decision authority on subjective health are identical in working circumstances. Job Demand-Control (JDC) model (Karasek, 1979) is a conceptual model guides all further research on job burnout. Futher this JDC model is expanded (Johnson and Hall, 1988) to include social justice. The JDC model projects the effect on the psychological and physiological reactions by the combined impact of high demand (Lange et al., 2003) and low skill discretion with decision authority.

\subsection{Stress Management Process}

Stress management can be implemented in multiple conducts, though; the process of stress management should include activities for assessment and treatment. The process may include program goals, manipulation activities to increase/decrease the stressors, accountability for occurrences and focus, workouts and a cycle of activities. A stress intervention program (Fig. 3) should be adopted by the organizations inculcating the viability of strategic access through information systems. Stress interventions (Harkness et al., 2005) can be performed to regulate the effects of stress causing factors. 
Vijaya Kumar, V.T.R. et al. / American Journal of Applied Sciences, 10 (1): 89-96, 2013

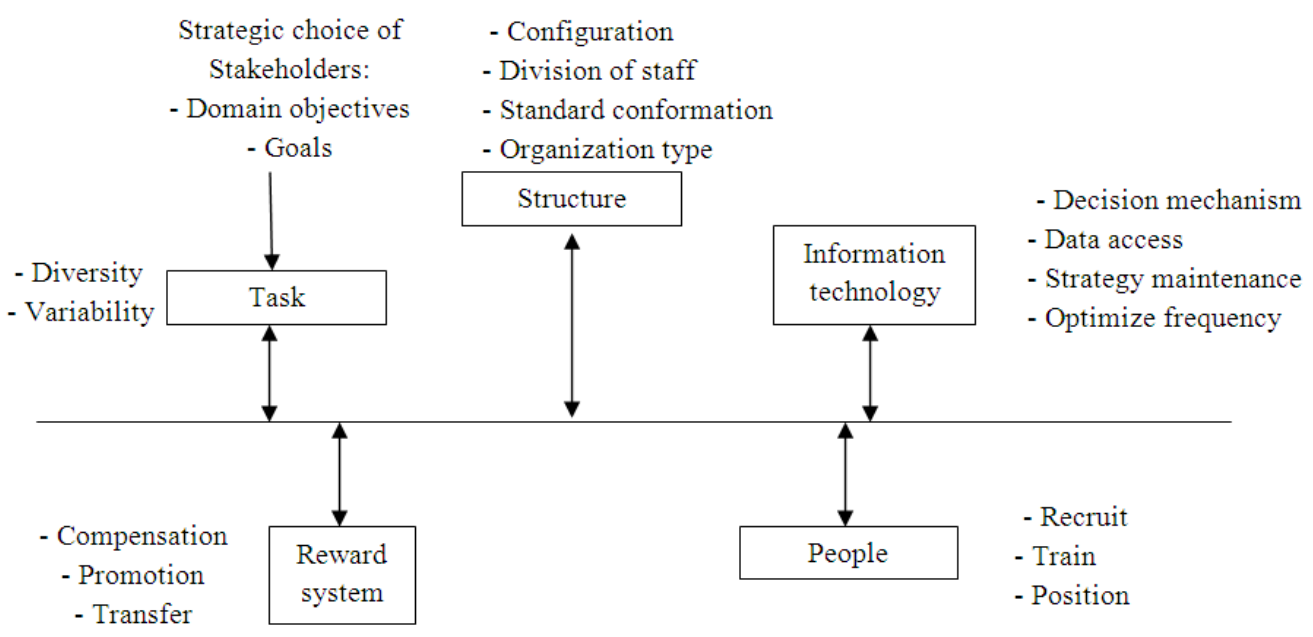

Fig. 2. Role of information system in organization work design

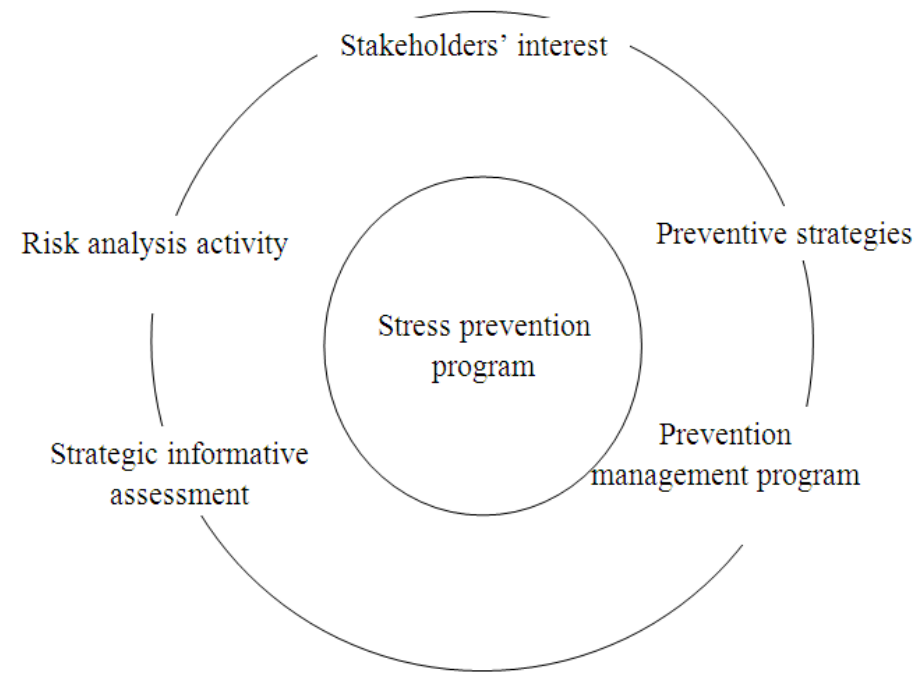

Fig. 3. Layout of stress intervention program

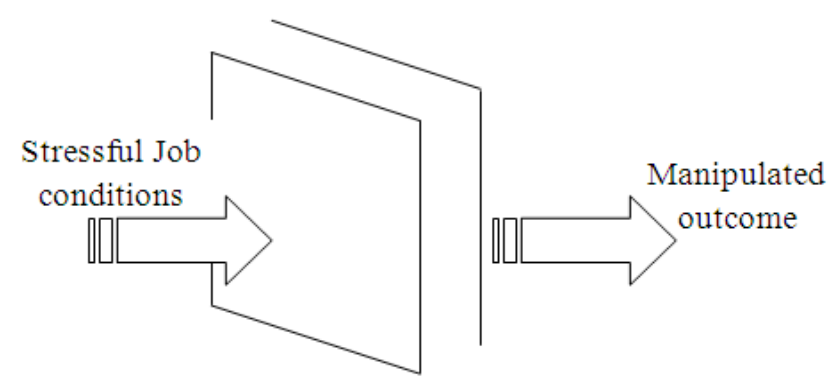

Individual and situational factors

(moderators)

Fig. 4. Individual and situational factor as moderators 
The stakeholders of highest interest are committed to employ organizational procedures to include preventive management methods in habitual operations of the company. The organization is expected to institute stress prevention strategies to establish an action plan to address the aims, responsibilities and resources. Interventions concentrating on individuals, teams and organization are designed and formalized. Collective programs for prevention management are applied to assess and sanctify primary intervention at work environment and individuals 'level'. A virtual participative approach is accommodated by providing privileged access to strategic informative assessment tools, at all level of employees. For the maintenance of achieved accountable benefits and to evaluate appraisal of work activities, a risk analysis activity is included. Some significant models on job stress evaluation are precisely doable.

\subsection{The Vitamin Model}

Certain job characteristics have its effect on mental health, resemble as the vitamins work in human body (Warr, 1987). On other hand, some characteristics are more beneficial at moderate levels, such characteristics are job demands, autonomy, social support, skill utilization, skill variety (Veldhoven et al., 2002).

\subsection{Demand Control Support Model}

Job control in its specialized area of workspace research has been mentioned as decision latitude, constructed by the sub-factors of decision authority and skill discretion. Karasek (1979), model reveals the decision authority as control over work situation and the possibility of using the potential skill, thus encompassing competencies are referred to skill discretion. The factor of social support was later added to this model to empirically prove its effectiveness (Cooper et al., 2001).

\subsection{The Cognitive Theory of Psychological Stress and Coping}

The transactional theory of Folkman and Lazarus (1980), work on the psychological stress and coping. The co-existence of the individual and his environment in a dynamic relationship has been examined in this Cognitive-Relational approach. These researchers classified the coping behavior into two categories. One classification was emotion-focused coping and the other is problem focused coping (attempts to consider the rational alternatives of problem solving approaches).

\subsection{The Job Demands-Resources Model}

Demerouti et al. (2001), classifies the psychosocial factors into global categories of job resources and job demands. Llorens et al. (2006), used the Job DemandsResources (JD-R) Model to identify the influence of illness and organizational commitment. The research exposed the fact about providing resource accord to the job condition and demand, would, influence health impairment and motivation.

\subsection{Demand-Skill-Support Model}

Veldhoven et al. (2005), proposed the Demand-SkillSupport Model (DSS), to predict stress in wide variety of occupations with the suitable usage of minimum factors. This model is robust on the data with considered factors of physical, time demands and social relationships (to share rationale information) along with skill utilization (self with combined skill of other individuals can be used). This is one of the model best fit for the current trend of IT sector where precise rationale are managed to share and re-use.

\subsection{DRIVE Model}

Mark and Smith (2009), proposed the Demands, Resources and Individual Effects (DRIVE) model. In this model the workplace and individual characteristics are conceived in terms of work demand-resources and individual demand-resources. This model compares the selected job characteristics and individual difference variables for a working population. The individual variables included for evaluation are job demands, social support, decision authority and skill discretion.

\subsection{Moderators for Satisfaction}

Most of the prominent models concentrating on demand and resources are significant in assessing the individual perception and his work environment. We propose a specialized method Moderators For Satisfaction (MFS) to find the degree of relationship between the factors give job satisfaction with the provided resources. The role of environment support, the way in which they moderate (Fig. 4) the impact of work demands and work control, can be assessed. The role of resources which in providing better environment is identified. In this suggested approach we concentrate on the resources provided for the individual to satisfy his job experience. This model work demand, work resources and skill discretion are all proposed to effect anxiety, depression and job satisfaction. This framework could include the personal demands such as self efficacy, 
locus of control, personality, environment-fit, experience, role conflict.

Many aspects of the stress cause model were considered as proven concepts through recent empirical studies. Notable relationships among their aspects are been revealed by survey. The study demand, work resources and skill variety are considered to vary with the change in other environmental variables. This study reveals such relationships that require certain tradeoff within considered criteria. We concentrate on five significant relationships:

- Work demand and Skill discretion relate to the outcomes

- Skill discretion and work resources relate to the outcomes

- Work demand and work resources relate to perceived job stress

- Level of perceived job stress relate to the outcomes

- Skill discretion, work demand and work resources moderate the outcomes

\section{CONCLUSION}

A final conclusion concerns the role of supportive environment (by providing decision tools) and how it may moderate the impact of work demands and work control. Strategic support would imperatively effective on high job demands when the informative support matches the demands of the job. It is also possible that skill discretion, at any situation, with decision support in moderating the effects of high demands on work control. Increased perceived job stress is associated with low control. Skill discretion and decision authority constructs the aspects of work control. MFS finds the moderated degree of relationship between work demands and satisfaction. MFS forecast the change in employee commitment, through the relationship among moderators. Controlling for the respective dependent measures at a time and other possible moderators the work pressure and emotional demands are made significantly and positively associated with change in psychological distress over time. By controlling the dependent measures, work engagement over time is significantly and positively associated with change in Moderators. Perceived job stress could vary for individual employees who are provided with similar resources and with same degree of demand. Acting as a moderator, the catalytic nature of perceived job stress manipulates the expected outcome. Skill discretion with work demand and the availability of required resources moderate the level of job satisfaction experienced by individuals. MFS predicts the changes in skill discretion, work pressure and perceived job stress over time. In spite of its limitations, the present study suggests that the MFS model may provide a useful theoretical foundation for the study of impact of strategically provided resources, but the environment-person fit need to be evaluated more independently according to the work domain, since, such factors emerge to be akin to satisfaction related to aspects.

\section{REFERENCES}

Al-Zhrani, S., 2010. Management information systems role in decision-making during crises: Case study. J. Comput. Sci., 6: 1247-1251. DOI: 10.3844/jcssp.2010.1247.1251

Balan, S.R.V. and M. Punithavalli, 2011. Decision based development of productline: A quintessence usability approach. J. Comput. Sci., 7: 619-628. DOI: $10.3844 /$ jcssp.2011.619.628

Blaug, R., A.M. Kenyon and R. Lekhi, 2007. Stress at Work. A Report Prepared for the Work Foundation's Principal Partners. 1st Edn., Work Foundation, London., pp: 93.

Cooper, C.L., P. Dewe and M.P. O’Driscoll, 2001. Organizational Stress: A Review and Critique of Theory, Research and Applications. 1st Edn., Sage Publications, Thousand Oaks, ISBN-10: 0761914811, pp: 270.

Demerouti, E., A.B. Bakker, F. Nachreiner and W.B. Schaufeli, 2001. The job demands-resources model of burnout. J. Applied Psychol., 86: 499-512. PMID: 11419809

Dibrell, C.C. and T.R. Miller, 2002. Organization design: The continuing influence of information technology. Manage. Decision, 40: 620-627. DOI: 10.1108/00251740210434016

Elfering, A., S. Grebner, N.K. Semmer, D. KaiserFreiburghaus and S.L.D. Ponte et al., 2005. Chronic job stressors and job control: Effects on eventrelated coping success and well-being. J. Occup. Organ. Psychol., 78: 237-252. DOI: 10.1348/096317905X40088

Folkman, S. and R.S. Lazarus, 1980. An analysis of coping in a middle-aged community sample. J. Health Soc. Behav., 21: 219-239. DOI: $10.2307 / 2136617$

French, J.R.P., R.D. Caplan and R.V. Harrison, 1982. The Mechanisms of Job Stress and Strain. 1st Edn., Wiley, Chichester, ISBN-10: 047110177X, pp: 160.

Gendolla, G.H.E., 2000. On the impact of mood on behavior: An integrative theory and a review. Rev. General Psychol., 4: 378-408. DOI: 10.1037/10892680.4.4.378 
Harkness, A.M.B., B.C. Long, N. Bermbach, K. Patterson and S. Jordan et al., 2005. Talking about work stress: Discourse analysis and implications for stress interventions. Work Stress, 19: 121-136. DOI: 10.1080/02678370500160068

Johnson, J.V. and E.M. Hall, 1988. Job strain, work place social support and cardiovascular disease: A cross-sectional study of a random sample of the Swedish working population. Am. J. Public Health, 78: 1336-1342. DOI: 10.2105/AJPH.78.10.1336

Jonge, J.D., C. Dormann, P.P.M. Janssen, M.F. Dollard and J.A. Landeweerd et al., 2001. Testing reciprocal relationships between job characteristics and psychological well-being: A cross-lagged structural equation model. J. Occupat. Organ. Psychol., 74: 29-46. DOI: 10.1348/096317901167217

Karasek Jr., R.B., 1979. Job demands, job decision latitude and mental strain: Implications for job redesign. Admin. Sci. Q., 24: 285-308. DOI: $10.2307 / 2392498$

Lange, A.H.D., T.W. Taris, M.A.J. Kompier, I.L.D. Houtman and P.M. Bongers, 2003. The very best of the millennium: Longitudinal research and the demand-control-(support) model. J. Occupat. Health Psychol., 8: 282-395. DOI: 10.1037/10768998.8.4.282

Lewin, K., 1951. Field Theory in Social Science. 1st Edn., Harper, New York, pp: 346. http://books.google.com.pk/books?id=PzMYAAAA IAAJ \&dq=Field $\% 20$ theory $\% 20$ in $\% 20$ social $\% 20$ scie nce\&source $=$ gbs_book_other_versions

Llorens, S., A. Bakker, W.B. Schaufeli and M. Salanova, 2006. Testing the robustness of Job demandsresources model. Int. J. Stress Manage., 13: 378391.

Mark, G.M. and A.P. Smith, 2009. Stress Models: A Review and Suggested New Direction. In: Occupational Health Psychology: European Perspectives on Research, Education and Practice, Houdmont, J. and S. Leka (Eds.), Nottingham University Press, Nottingham, ISBN-10: 1904761828, pp: 111-144.

Marmot, M., 2005. Status Syndrome. 1st Edn., New York Bloomsbury Publishing, London, ISBN-10: 0747574081, pp: 320.

McHugh, M. and S. Brennan, 1992. Organization development and total stress management. Leadership Organ. Dev. J., 13: 27-32. DOI: 10.1108/EUM0000000001173
Muraven, M. and R.F. Baumeister, 2000. Self-regulation and depletion of limited resources: Does self-control resemble a muscle. Psychol. Bull., 126: 247-259. PMID: 10748642

Narayanan, L., S. Menon and P.E. Spector, 1999. Stress in the workplace: A comparison of gender and occupations. J. Organ. Behav., 20: 63-73. DOI: 10.1002/(SICI)1099-1379(199901)20:1<63::AIDJOB $873>3.0 . \mathrm{CO} ; 2-\mathrm{J}$

Osipow, S.H., 1998. Occupational Stress Inventory: Professional Manual. 1st Edn., Psychological Assessment Resources, Odessa, pp: 63.

Pareek, U.R., 2002. Training Instruments For Hrd and Od. 2nd Edn., Tata McGraw-Hill, New Delhi, ISBN-10: 0070483248, pp: 861.

Parker, D.F. and T.A. Decotiis, 1983. Organizational determinants of job stress. Organ. Behav. Perfor., 32: 160-177. DOI: 10.1016/0030-5073(83)90145-9

Pestonjee, D.M., 1999. Stress and Coping: The Indian Experience. 2nd Edn, Sage Publications, New Delhi, ISBN-10: 0761993126, pp: 321.

Robbins, S.P. and T. Judge, 2007. Organizational Behavior. 12th Edn., Prentice Hall PTR, New York, ISBN-10: 1405846607, pp: 759.

Rutter, H., J. Herzberg and E. Paice, 2002. Stress in doctors and dentists who teach. Med. Educ., 36: 543-549. DOI: 10.1046/j.1365-2923.2002.01229.x

Schaufeli, W.B. and A.B. Bakker, 2004. Job demands, job resources and their relationship with burnout and engagement: A multi-sample study. J. Organ. Behav., 25: 293-315. DOI: 10.1002/job.248

Seyle, H., 1956. The Stress of Life. 1st Edn., McGrawHill, New York, pp: 324.

Seyle, H., 1973. The evolution of the stress concept. Am. Sci., 61: 692-699. PMID: 4746051

Singh, J., 2000. Performance productivity and quality of frontline employees in service organizations. J. Market., 64: 15-34. DOI: 10.1509/jmkg.64.2.15.17998

Srivastav, A.K., 2009. Heterogeneity of organisational climate. Res. Pract. Hum. Resource Manage., 17: 113.

Sutherland, L.F., G.J. Fogarty and R.T. Pithers, 1995. Congruence as a predictor of occupational stress. J. Vocat. Behav., 46: 292-309. DOI: 10.1006/jvbe.1995.1022

Veldhoven, M.V., J.D. Jonge, S. Broersen, M. Kompier and T. Meijman, 2002. Specific relationships between psychosocial job conditions and job-related stress: A three-level analytic approach. Work Stress, 16: 207-228. DOI: 10.1080/02678370210166399 
Veldhoven, V.M., T.W. Taris, J. Jonge and S. Broersen, 2005. The relationship between work characteristics and employee health and well-being: How much complexity do we really need. Int. J. Stress Manage., 12: 3-28. DOI: 10.1037/1072-5245.12.1.3

Vohs, K.D. and R.J. Faber, 2007. Spent resources: Self-regulatory resource availability affects impulse buying. J. Consumer Res., 33: 537-547. DOI: $10.1086 / 510228$
Wan, E.W. and N. Agrawal, 2011. Carryover effects of self-control on decision making: A construal-level perspective. J. Consumer Res., 38: 199-214. DOI: 10.1086/658471

Warr, P.B., 1987. Work, Unemployment and Mental Health. 1st Edn., Clarendon Press, Oxford, ISBN10: 0198521588 , pp: 361 . 